\title{
Key aspects of protection of digital rights of the individual related to the development of the cryptocurrency sphere
}

\author{
Oleg Anatolyevich Stepanov ${ }^{11}$, Evgeniya Nikolaevna Prokhorova ${ }^{2}$, Stanislav Aleksandrovich \\ Vasilyev $^{3}$, and Vartan Samsonovich Virabov ${ }^{4}$ \\ ${ }^{1}$ Institute of Legislation and Comparative Law under the Government of the Russian Federation, \\ Centre of Criminal, Criminal Procedure Legislation and Case History, Moscow, Russia \\ ${ }^{2}$ Kaliningrad branch of Saint-Petersburg University of MIA of Russia, Chair of Criminal Proceeding, \\ Kaliningrad, Russia \\ ${ }^{3}$ Sevastopol State University, Department of Constitutional and Administrative Law, Sevastopol, \\ Russia \\ ${ }^{4}$ Contractual and Legal Department of MIA of Russia, Moscow, Russia
}

\begin{abstract}
The main objective of the research is to study the scientific problem of public importance related to the protection of digital rights of the individual in the modern conditions. Due to the development of the cryptocurrency sphere, the problem of protection of digital rights of the individual becomes one of the most urgent. The subject studied comprehensively by the authors is the sphere of activity related to the protection of digital rights of the individual from unlawful encroachments. The methodological base of the research consists of the methods of logic allowing to consider the diverse relations in the cryptocurrency sphere and also the analysis of the legislation, study of the documents, study of the electronic information resources. The result of the research is making recommendations regarding the protection of digital rights of the individual related to the development of the cryptocurrency sphere. Furthermore, the authors emphasize the provision of harmonization of the interests of the state and the individual in the cryptocurrency sphere. The novelty of the paper is that the obtained results of the research have not been published before in the literary references and can serve as a guide mark for the further scientific search in the sphere of protection of digital rights of the individual.
\end{abstract}

Keywords: development of cryptocurrency sphere, digital rights of the individual

\section{Introduction}

In 2020 the volume of deals with cryptocurrencies in Russia doubled and was more than 65 mln US dollars and the number of users of the crypto market from Russia increased at 45 percent. From February 08-14, 2021 the volume of transactions with bitcoins exceeded 16

\footnotetext{
${ }^{1}$ Corresponding author: o stepanov28@mail.ru
} 
mln rubles. Furthermore, the exchange rate of bitcoin continued to grow and on February 21, 2021 it reached the point of 58 thousand US dollars and according to the forecast estimations, it can grow up to 100-200 thousand US dollars [1]. Meanwhile, it was in 2019 when the Financial Action Task Force on Money Laundering (FATF) renewed its recommendations regarding the regulation of the digital assets in its "Guideline of risk-oriented approach to the digital assets and providers of digital services" 2 .

The new amendments do not only tighten control of the activity of the providers of the cryptocurrency market and also the individuals engaged in the sale of cryptocurrency but also require tracing and blocking of the operations with the digital assets for the individuals and organizations under international sanctions (list of UN) by analogy with the current norm for the classical financial organizations [2].

The presented research covers the issues related to the analysis of the protection of digital rights of the individual in the cryptocurrency sphere. The digital rights of the individual are laws of obligations and other rights the content and conditions of which are determined according to the rules of the information system that corresponds to the features established by the law [3].

The article focuses its attention on the theoretical consideration of this problem. The hypothesis of the research is based upon the necessity to use the new approaches related to the protection of rights of the individual in the cryptocurrency sphere. Basing upon this, the objective and tasks of the research are determined by the demands of the development of the complex approach to the solution of the problem of protection of rights of the individual in the cryptocurrency sphere. The achievement of the stated objective is related to the solving of the following scientific and practical tasks: formulation and grounding of the main provisions related to the protection of rights of the individual in the cryptocurrency sphere; proposing of measures to eliminate the consequences of the unlawful acts in the said sphere.

\section{$2 \quad$ Methods}

The methodological base of the research consists of the methods of logic allowing to consider the diverse relations in the cryptocurrency sphere and also the analysis of the legislation, study of the documents, study of the electronic information resources. The works of such authors as Vasilyeva, Grigoryev, Zharova, Zorkin, Kovler, Pechegin, Prokhorova, Stepanov, Shanakhan [4-14] served the theoretical and methodological base of the research.

\section{$3 \quad$ Results and discussion}

The attractiveness of cryptocurrencies and other monetary surrogates is that the procedure of the corresponding payments is still not regulated in the legislation of the most countries. It does not only eliminate the barriers for international transactions but also creates the conditions for withdrawal of money abroad without paying any fees to banks and also without paying taxes [2]. It should also be mentioned that already in July 2018 the countries - members of the "G20 signed the agreement according to which the standard of anti-money laundering in the cryptocurrency sphere shall be developed [10, p. 128].

\footnotetext{
${ }^{2}$ Following the Resolution No. 1617 dated 2005 of the UN Security Council, Recommendations of FATF are obligatory for all states - members of the UN
} 
The regulatory activity in the considered sphere shall be directed to the provision of the quality of the issued laws and also to the increase of information awareness of the citizens about the development and results of the implementation of the normative legal documents.

On July 31, 2020 in Russia the Law No. 259-FZ (hereinafter - DFA Law) [15] was passed that regulates the cryptocurrencies and other virtual assets and provides the issue and circulation of digital financial assets (tokens) recognized as digital rights.

Taking into account the abovementioned circumstances in relation to such assets the scientific researches are required that are related to the protection of the digital rights of the individual. Besides, the appearance of these rights rises the urgent issue of harmonization of interests of the state and the individual in the cryptocurrency sphere as the DFA Law establishes the requirements for the "business reputation" to the executive bodies of the information system. Such requirements, in particular, include no records of unexpunged or unspent conviction, no records of administrative or criminal prosecution due to the bankruptcy, no record of involving into extremist activity or terrorism.

Therefore, it is evident to reinterpret the role of the right as a whole and the criminal law in particular [8, pp. 191-195] when implementing the strategy directed to the prevention of social strain in the society due to the development of the cryptocurrency sphere [11, pp. 107-108].

According to Zorkin "the applied counter-measures (technologies) against criminality shall not become the excessive restrictions encroaching its essence (main content) of the constitutional right for the information and freedom of human behaviour in the Internet under its protection [6].

The fundamental researches in the field of digital technologies are connected to the appearance of the concept of a technological singularity that is the reaching by mankind of such level of the development of the scientific and technological base when the scientific progress is no longer clear for the individual [16]. One of its features is the existence of a so-called world-system united by the national (supranational) relations and having a different quality of management. The technological singularity presupposes the integration of an individual and a machine that means the transformation of a person into a unified "digital personality" having a more active connection with the information space than with reality [14].

Taking into account this circumstance and from the point of view of the protection of human rights from the negative consequences related to the development of the cryptocurrency sphere the issues of sufficiency of the legal regulation mechanisms of digitalization process performing the transition of the state institutions and economic relations to the information direction of the development require the independent analysis [4].

During the conference "To manage the game rules - the impact of the artificial intelligence on the human rights, democracy and rule-of-law state" held in Helsinki on February 26-27, 2019 the main accent was focused on the provision of the legal environment for the use of the new information technologies and democratic control of those who own such technologies [7, pp. 146-150]. The Bulletin of the European Court of Human Rights has already a definition of the term "digital environment" that includes the information and communication technologies, including the Internet, mobile technologies and devices related to them and also the digital networks, databases, content and services" [17]. All this actually presupposes the creation of the digital personality profile (DPP).

The statutory acts (DGPR) that came into force on May 25, 2018 - EU Regulation 2016/679 and also the EU Directive 2016/680 require the European companies involved in tracing and digital profiling to observe the regulation according to which the European users 
has the right to check their data and edit them in case they do not agree with the information obtained [5, pp. 55-61].

This program is not similar to the Chinese program of "social credit" that accumulates the maximum data of the citizens beginning from their income till their social behavior when every person has his rating related to the possibility of some serious restrictions including also hiring. These actions have a secondary managerial character as they are connected to the possibility of provision and also refusal to provide any information to the hired person.

Such legal relations include three types of objects, i.e.:

- related to the processes of creation and transformation of the evidentiary information;

- related to the storage and protection of personal data;

- related to the processes of transition of evidentiary information of the different levels of access.

With that, the holder of the secondary right, in comparison with the other holders of subjective rights has an exclusive ability to cause the consequences related to the appearance, change or termination of rights and obligations by his own actions. However, the secondary right is not a subjective right as the secondary rights of one side are not corresponded to the obligation of the subjects of the other side and also the relations of it with this right [9, pp. 124-125].

In respect to DPP within the frameworks of the problem of protection of individual rights in the cryptocurrency sphere, this circumstance shall be considered through the prism of a fair estimation of actions of the individual by the society, at least until the appearance of the hardware and software which power can be compared with the human brain [12].

We shall mention that in China all users of the Internet are obliged to identify themselves producing the identity card. Their data are recorded specifying the address of their PC and time spent in the Internet. The mentioned information is stored during several weeks and provided following the request to the competent government authorities. In Russia, there is no obligatory registration for users. However, the current legislation provides the obligatory specification of information regarding the owners of the sites. Therefore, many sites introduce the requirement for identification of the users using the procedures of "registration/authorization". Meanwhile the experience of the USA, Poland, Israel where the judicial authorities are authorized to control the security support in the information field show that the complexity of counteraction to the unlawful phenomena is stipulated by the peculiarities of the technical organization of the Internet network allowing registration of the domain names of the site in one country but placing the information about it in the other country.

The major part of the Internet-services based upon the cloud technologies is a system of legal relations architecturally distributed among several jurisdictions and the users interacting within the frameworks of such Internet-service belong to different jurisdictions. The problem of determination of the jurisdiction presupposes the consideration of the issue - in the frameworks of what particular relations the servers are located, through what jurisdictions data transfer is routing and also in what jurisdictions the access to it is allowed. At the same time, it should be taken into account what character these "clouds" have private or public.

Besides, from the point of view of localization of unlawful acts the problem of exterritoriality of legal provisions in respect to the content of the Internet resources oriented to the audience consisting of the population of the other country requires consideration. This circumstance is important for the estimation of the possibility of law enforcement of 
one legal system to the relations within the frameworks of which one or several subjects belong to the other jurisdiction [13, pp. 4-23].

Without taking into account these key aspects it is difficult to talk about the possibility to provide the protection of rights of the individual in the cryptocurrency sphere.

\section{Conclusion}

The conclusions formulated by the authors do not only develop the theoretical and practical aspects of protection activity of rights of the individual in the cryptocurrency sphere but can also become a guide mark for prevention of the negative factors in the conditions of the intensive development of the digital technologies. This circumstance determines the range of issues studied by the authors.

\section{References}

1. Bitkoinu predskazali vzlet do 200 tysyach dollarov [Bitcoin was predicted the rise up to 200 thousand dollars] (2021). Accessed on: June 25, 2021. [Online]. Available: https://360tv.ru/news/dengi/bitkoinu-predskazali-vzlet-do-200-tysjach-dollarov/

2. O.A. Stepanov, A.O. Stepanov, Modern Law, 12, 70-74 (2020)

3. L. Novoselova, A. Gabov, A. Savelyev et al., Law, 5, 31-55 (2019)

4. L.N. Vasilyeva, A.V. Grigoryev, Journal of the Russian Law, 10, 40-58 (2020)

5. A.K. Zharova, Laywer, 3, 55-61 (2020)

6. V. Zorkin, Rossyiskaya Gazeta - Capital issue, 115 (2018)

7. A.I. Kovler, Bulletin of the European Court of Human Rights, 6, 146-150 (2019)

8. D.A. Pechegin, Law. Journal of the Higher School of Economics, 4, 181-195 (2018)

9. E.N. Prokhorova, Pravovye aspekty obespecheniya dostupa $k$ informatsii ogranichennogo dostupa i ee zashchity v sovremennykh usloviyakh [Legal aspects of providing an access to the information of restricted access information and its protection in the modern conditions], in Law and Information: theoretical and practical issues. Collection of works of the International Scientific and Practical Conference. Series "Electronic legislation", 9, 124-125 (President's library, Saint-Petersburg, 2020)

10. O.A. Stepanov, Modern Law, 6, 125-129 (2019)

11. O.A. Stepanov, Modern Law, 1, 107-108 (2020)

12. O.A. Stepanov, D.A. Pechegin, Law. Journal of the Higher School of Economics, 4, 83-97 (2017)

13. O.A. Stepanov, Law. Journal of the Higher School of Economics, 3, 4-23 (2018)

14. M. Shanakhan, Technological singularity (trans. from English) (Publishing group "Tochka", Alpina Publisher, Moscow, 2017)

15. Federal Law 259-FZ dated 31.07.2020 "Of digital financial assets, digital currency and making amendments in particular legislative acts of the Russian Federation"

16. G. Leongard, Tekhnologii protiv cheloveka [Technologies against human]. Accessed on: June 25, 2021. [Online]. Available: https://philologist.livejournal.com/10556935.html

17. Bulletin of the European Court of Human Rights, 12, 117 (2018) 